\title{
ANÁLISE DO PERFIL DOS DISCENTES DO CURSO BACHARELADO EM CIÊNCIA E TECNOLOGIA E SUA RELAÇÃO COM A APRENDIZAGEM EM CÁLCULO
}

\author{
ANALYSIS OF THE PROFILE OF STUDENTS IN SCIENCE \\ AND TECHNOLOGY COURSE AND THEIR RELATIONSHIP \\ WITH LEARNING IN CALCULUS
}

ANÁLISIS DE LOS PERFILES DE LOS CURSOS ESCOLARES DISCENTENTES EN CIENCIA Y TECNOLOGÍA Y SU RELACIÓN CON EL APRENDIZAJE EN EL CÁLCULO

\begin{abstract}
Davi Euclides De OliveIra ${ }^{\mathrm{I}}$ JANNESON JOSÉ FERREIRA DE LIMA ${ }^{\mathrm{I}}$

Paulo Henrique das Chagas Silva ${ }^{\mathrm{I}}$ 'Universidade Federal Rural do Semi-Árido (UFERSA), Pau dos Ferros/RN-Brasil
\end{abstract}

Resumo Os cursos de Ciências Exatas são marcados por altos índices de reprovação e desistência, em grande parte, por causa da dificuldade dos alunos em relação especialmente às disciplinas de Cálculo. Para contornar essa situação, aconselha-se que se conheça a população dos discentes e se desenvolvam metodologias apropriadas em torno desse conhecimento. Neste viés, este trabalho tem por objetivo analisar o perfil discente do curso de Ciência e Tecnologia de uma Universidade Federal no interior do RN, compreendendo seus anseios na trajetória acadêmica. Para essa pesquisa, realizou-se uma análise socioeconômica e fatorial dos discentes, através da aplicação de questionário online, no qual foi obtido uma amostra de 78 respondentes. Analisando os dados em escala Likert pelo programa PSPP, verificou-se a ocorrência de quatro perfis estudantis: 1) que declaram que eram bons em Matemática no Ensino Médio, 2) que organizam seu tempo disponível da melhor forma possível, 3) que são participativos nas aulas e 4) que possuem identificação com o curso. Esses grupos congregam $61,99 \%$ da população estudada e foi apurado, para cada um desses, algumas justificativas para os resultados acadêmicos acima descritos. Assim, o presente artigo disponibiliza um norteamento para implementação de práticas de ensino que corroborem com o perfil de alunos encontrados pela pesquisa.

Palavras-chaves: Perfis acadêmicos; Cálculo; CiênCia e Tecnologia; Análise fatorial.

Comunicações Piracicaba |v. 28 |n. 2 |p. 57-75 | maio-ago. 2021 DOI: http://dx.doi.org/10.15600/2238-121X/comunicacoes.v28n2p57-75 
ABSTRACT Exact Sciences courses are marked by high failure and dropout rates, largely because of the students' difficulty in relation especially to the Calculus subjects. To get around this situation, it is advisable to know the student population and develop appropriate methodologies around this knowledge. In this perspective, this work aims to analyze the student profile of the Science and Technology course of a Federal University in the interior of RN, understanding their aspirations in the academic trajectory. For this research, a socioeconomic and factorial analysis of the students was carried out, through the application of an online questionnaire, in which a sample of 78 respondents was obtained. Analyzing the data on the Likert scale using the PSPP program, four student profiles were found: 1) who declare they were good at high school mathematics, 2) who organize their available time in the best possible way, 3) who are participatory in classes and 4) who have identification with the course. These groups comprise $61.99 \%$ of the studied population and, for each of these, some justifications for the academic results described above were found. Thus, this article provides guidance for implementing teaching practices that corroborate the profile of students found by the research.

Keywords: Academic profiles; Calculation; Science and technology; Factor ANALYSIS.

Resumen Los cursos de Ciencias Exactas están marcados por altas tasas de reprobación y abandono, en gran parte debido a la dificultad de los estudiantes en relación especialmente con las asignaturas de Cálculo. Para esta situación, es recomendable conocer a la población estudiantil y desarrollar metodologías adecuadas en torno a este conocimiento. En esta perspectiva, este trabajo tiene como objetivo analizar el perfil del estudiante de la carrera de Ciencia y Tecnología de una Universidad Federal en el interior de RN, entendiendo sus anhelos en la trayectoria académica. Para esta investigación se realizó un análisis socioeconómico y factorial de los estudiantes, mediante la aplicación de un cuestionario online, en el que se obtuvo una muestra de 78 encuestados. Analizando los datos en la escala Likert utilizando el programa PSPP, se encontraron cuatro perfiles de estudiantes: 1) que declaran ser buenos en matemáticas de secundaria, 2) que organizan su tiempo disponible de la mejor manera posible, 3) que sean participativos en las clases y 4) que tener identificación con el curso. Estos grupos comprenden el $61,99 \%$ de la población estudiada y para cada uno de ellos se encontraron algunas justificaciones de los resultados académicos descritos. Así, este artículo brinda orientación para implementar prácticas docentes que corroboren el perfil de estudiantes encontrado por la investigación.

Palabras clave: Perfiles académicos; Cálculo; Ciencia y Tecnología; Análisis facTORIAL.

\section{INTRODUÇÃo}

Nos últimos tempos, cresceu-se o interesse em analisar e compreender o perfil dos estudantes ingressantes nas universidades brasileiras. Como mostrado no trabalho de Oliveira et al. (2016) a partir de uma pesquisa com os discentes, buscou-se estimar e compreender o perfil socioeconômico, de escolaridade e qual a importância dos cursos de Engenharia 
de Produção para os ingressantes de uma dada universidade. Dessa forma, tal mecanismo visa obter dados e diretrizes que façam com que a coordenação do curso tenha em mãos características comuns aos ingressantes no curso. O elemento a ser analisado varia em cada pesquisa, que pode compreender desde análise de aspectos sociais e econômicos dos discentes até procurar entender qual é a realidade e os anseios dos estudantes da Educação a Distância, conforme apresentado por Godoi e Oliveira (2016).

Não diferente, a Área das Ciências Exatas tem recebido diversos trabalhos voltados a essa temática, especialmente no que se refere às dificuldades apresentadas pelos discentes ao longo de tais cursos. Como em Araujo (2002), o qual explicita sobre aspectos do perfil de discentes ingressantes nas Área de Exatas e Engenharia da PUC-Campinas e a necessidade de mudanças de metodologia nesses cursos. $\mathrm{O}$ autor ainda promove a reflexão acerca das realidades de níveis educacionais anteriores dos discentes, o que, segundo o mesmo, justifica essas falhas de aprendizagem.

Nessa vertente, apesar de necessário para os alunos de cursos como Engenharias, Matemática, Física ou Economia, o Cálculo Diferencial e Integral, da forma que é usualmente trabalhado nas universidades brasileiras, apresenta um certo desânimo relacionado ao seu grau de dificuldade. Entretanto, segundo Rafael (2017), essa visão sobre o cálculo é dada, na maior parte dos casos, devido a uma bagagem pessimista ou angustiante que é adquirida pelo contato com veteranos da instituição e, já nas primeiras aulas, sem nem ter visto o conteúdo em sua totalidade, fomenta-se inquietações e desistências nesta disciplina. Assim, este repúdio é decorrente da fama que a disciplina tem dentro da própria universidade, devido a sua dificuldade, acaba sendo um desafio na vida dos discentes, o que pode servir como bloqueio mental para o aprendizado efetivo dos assuntos da disciplina.

Através dessas considerações, Evangelista et al. (2018) mostram uma problemática ao afirmar que o alto índice de reprovações em disciplinas de cálculo constitui uma realidade que incomoda docentes e discentes nos cursos nas mais diversas universidades brasileiras. Notas baixas, alunos reprovados repetidamente, professores com dificuldades para encontrar uma metodologia mais acessível, dentre outros fatores são, em conjunto, o motivo de tamanha preocupação.

Quando se trata de uma problemática como essa, deve ser analisado quais são as motivações dos alunos, pois, como Bzuneck (2018) aponta na psicologia educacional, muitos sentimentos negativos estão presentes no ambiente emocional dos alunos. Dentre essas emoções, de acordo com o autor, pode-se citar a raiva, a vergonha, o tédio e a ansiedade, que, em especial, tem maior destaque frente às demais. A raiva e a vergonha estão ligadas diretamente ao rendimento insatisfatório do aluno, no qual ele acaba se culpando por notas baixas e se envergonha disso. O tédio se relaciona ao desprazer em realizar algo e, como consequência, o aluno entediado tem distrações com mais facilidade e limita o aprendizado. Já a ansiedade está associada a tensão e desconforto, acompanhados por medo devido a uma quebra de expectativas, sendo essa emoção a que mais preocupa os estudiosos.

Segundo Lavor e Martins (2020), os discentes associam suas dificuldades e baixo rendimento a suas emoções, sendo necessário um apoio dos docentes às questões emocionais dos alunos. Para que o rendimento seja satisfatório, é necessário que os alunos estejam com uma qualidade emocional equilibrada. Os autores ainda complementam que algumas falas 
de alunos apontam transtornos de ansiedade por motivos de emoções abaladas devido uma pressão familiar, social e psicológica que o discente enfrenta.

Visto isso, é essencial mudanças de postura e estratégias em relação ao ensino-aprendizagem de Cálculo I, objetivando a alteração na percepção negativa que o componente curricular porta e as metodologias que majoritariamente só se tornam efetivas quando procuram entender o pensamento do público-alvo. Como consequência e trilhando um procedimento diferente em relação a diversos outros trabalhos acadêmicos da área - que encorajam a utilização de didáticas para sanar esses problemas, como o uso de metodologias ativas, implementação de projetos de pesquisa/extensão, cursos de formação -, a pesquisa do presente trabalho propõe estabelecer e refletir sobre o perfil dos alunos que optam por cursar o Bacharelado Interdisciplinar em Ciência e Tecnologia (CeT) de uma universidade localizada na região do Alto Oeste Potiguar a partir de um autorretrato deles, refletindo sobre aspectos sociais, as dificuldades de ensino-aprendizagem e sobre suas motivações; assim como aferir sobre as impressões e vivências relacionadas ao componente curricular Cálculo I.

A intenção é que, fundamentado nisso, se conheça um perfil norteador sobre quem são os discentes deste curso, de tal forma que seja plausível apresentar uma justificativa sobre os resultados indesejados nas disciplinas de cálculo. Por fim, embasado nesse conhecimento, o presente artigo ainda buscará fomentar resultados analíticos e estatísticos que podem estimular e servir de subsídio para a formulação de estratégias educacionais que contemplem o aluno de CeT de tal universidade alicerçado em sua própria realidade.

\section{SITUAÇÃo EDUCACIONAL BRASILEIRA}

Paralelo a essas considerações, sabe-se que a educação brasileira se encontra como deficitária em todos os níveis educacionais. Dados do Portal Todos Pela Educação do Governo Federal $^{1}$ (BRASIL, 2019a) informam que apenas 9,1\% dos alunos do $3^{\circ}$ ano do Ensino Médio no ano de 2017 tinham conhecimentos adequados em Matemática e, durante os últimos 10 anos, a Educação Brasileira segue estagnada numa faixa percentual próxima a esse valor. Infelizmente, tais realidades refletem e desencadeiam-se durante o Ensino Superior, especialmente em graduações nas Ciências Exatas.

Vários estudos como os de Trevisan e Mendes (2018), Oliveira e Raad (2012) e Oliveira e Madruga (2018) debatem sobre a problemática acerca das reprovações dos discentes em Cálculo I e como essa recorrência afeta nos índices de desistências das universidades, haja visto que os primeiros contatos com esses componentes ocorrem ainda quando calouros. Dessa forma, os autores supracitados comentam sobre estratégias e metodologias sobre as quais os professores devem pautar suas aulas, bem como ações de extensão que as universidades podem adotar, como cursos niveladores aos discentes ingressantes (Matemática Zero/Pré-Cálculo), articulando mecanismos para suprir as necessidades deixadas pelo Ensino Médio Brasileiro.

Rosa et al. (2019) exemplificam essa situação ao analisar a disciplina Cálculo 1A na UFG, que tem uma carga horária de 96 horas e os seguintes conteúdos ministrados: núme-

-https://www.todospelaeducacao.org.br/conteudo/meta-3-em-10-anos-aprendizado-adequado-ensino-medio-segue-estagnado-avancos-5-ano-fundamental 
ros reais; funções reais de uma variável real e suas inversas; noções sobre cônicas; limite e continuidade; derivadas e aplicações; polinômio de Taylor; integrais, técnicas de integração; integrais impróprias; e aplicações. Esse trabalho, ao analisar dados de 2010 a 2016, conclui que a média de reprovações se mantém em todos os períodos acima ou igual a 56\%, fato justificado por Rosa et al. (2019) pela quebra de expectativa dos alunos e professores em relação à matemática básica. Desse modo, essa frustração se desenvolve com choque de realidade que os alunos têm quando se deparam com cálculos mais complexos e densos na disciplina analisada.

Bezerra e Gontijo (2020) complementam essas discussões mostrando que essas altas taxas de reprovação no Cálculo I ainda estão bem presentes no contexto atual das universidades, promovendo a discussão da perspectiva dos docentes para essa realidade. Nessa tangente, resumidamente, os professores citaram causas como a falta de uma base acadêmica bem estruturada por parte dos alunos, bem como a imaturidade e motivação deles. Além disso, destacam-se dificuldades habituais na aprendizagem de conceitos da disciplina. Interessantemente, esses autores discorrem sobre ajustes aplicáveis para a melhoria contínua desse processo de ensino-aprendizagem, que incluíram readaptações nos instrumentos avaliativos utilizados, nas interações entre os professores e os alunos e de revisões no planejamento geral da disciplina a cada semestre.

Sabendo que essa problemática é muito presente nas escolas e universidades, é possível traçar planos para modificar esse cenário. De modo mais abrangente se faz necessário conhecer a população que está sendo estudada. Firmado nisso, Azevedo (2020) afirma que é importante uma análise de perfil de ingressantes nos cursos de graduação, uma vez que efetiva a implantação de políticas públicas em educação e que é possível apresentar um diagnóstico que permita modificar os cenários, sendo apropriada através de um olhar sociológico dos estudantes, visando as perspectivas profissionais e as dificuldades apresentadas. É importante ressaltar que esse tipo de análise também é viável para os alunos não ingressantes.

A partir de um olhar mais criterioso para analisar perfis de alunos, é possível perceber que existem alunos que lhes convém serem mais participativos em aulas e separarem um tempo extra para exercícios e estudos de fixação. Para Daher (2017), é defendido que os alunos são os responsáveis finais pelo processo de aprendizagem, cabendo ao professor somente ser o agente intermediador desse processo, o que justifica a essencialidade de conhecer os perfis dos discentes. Assim, afirma-se que para um bom processo de aprendizagem é necessário um equilíbrio de esforços entre professores e alunos.

Nessa perspectiva, observa-se a necessidade da adoção de práticas educacionais que inovem o Ensino Superior brasileiro. Peculiarmente, há a necessidade do debate acerca de aspectos motivacionais dos discentes, bem como compreender qual a visão dos discentes acerca das disciplinas ou do curso como um todo. Sob essa lógica, Coutinho et al. (2019) enfatiza que, visando um maior engajamento dos discentes e aproximação do conteúdo à resolução de problemas reais, o professor deve explorar a utilização de tecnologias, alterando sua postura e metodologia de ensino para o fortalecimento de ambientes solidários e interativos. 


\section{O Curso Interdisciplinar Cî̂nCIA e TeCnologia}

Conforme encontrado no site $^{2}$ da Universidade na qual foi realizada a pesquisa (BRASIL, 2019b), a instituição oferece ao público vagas para o curso de Bacharelado Interdisciplinar em Ciência e Tecnologia - BCT - através do Sistema de Seleção Unificada (SISU), curso de duração de seis períodos diurnos ou sete períodos noturnos. Este curso tem por objetivo a melhoria do acesso, permanência e qualificação de estudantes nos cursos de graduação. Com isso, a instituição divide a graduação em Engenharia em 2 ciclos, sendo o primeiro a conclusão no $\mathrm{BCT}$ e, para o segundo ciclo, o discente poderá ingressar nos seguintes cursos: Engenharia Civil, Engenharia Mecânica, Engenharia Elétrica, Engenharia Química, Engenharia da Produção, Engenharia do Petróleo, Engenharia Ambiental e Sanitária e Engenharia da Computação. Assim, o curso de BCT contém disciplinas obrigatórias que constituem a base das engenharias, como Cálculos, Físicas e Químicas.

Nesse cenário, esse curso visa a formação de um profissional generalista e com forte base científica. Além disso, o discente deverá concluir disciplinas optativas que estão mais direcionadas a Engenharia que deseja cursar, tendo um direcionamento maior para tal no decorrer do curso. De fato, o segundo ciclo é opcional ao discente, mas o BCT atua como um redutor de evasão para os cursos de segundo ciclo e amplia a qualidade da formação em cursos superiores na região na qual está inserida a instituição pesquisada.

\section{Metodologia}

Para o desenvolvimento do presente trabalho realizou-se uma pesquisa qualitativa com os discentes do curso bacharelado Interdisciplinar em Ciência e Tecnologia de uma universidade localizada na região do Alto Oeste Potiguar. Para isso, visando um mecanismo de coleta de dados confiável, segura - haja visto a pandemia do COVID-19 que o presente ano enfrenta - e acessível, criou-se um questionário com 25 questões nos Formulários Google (Tabela 01), que esteve disponível durante o período de 15/06/2020 até 23/06/2020, divulgado para todos os discentes supracitados a partir de e-mail da Coordenadora do Curso.

A metodologia de coleta de dados por entrevistas online durante a pandemia do COVID-19 é discutida por Schmidt et al. (2020), os quais retratam suas potencialidades e seus desafios de implementação, uma vez que, pela alta transmissibilidade do vírus e consequente isolamento social, torna-se uma das únicas ferramentas plausíveis de coleta de dados. Dentre as forças relativas a essa técnica, destacaram as possibilidades de maior abrangência geográfica, baixos recursos financeiros investidos na entrevista, redução de tempo na coleta de dados e maior segurança de participantes e pesquisadores frente ao contexto de pandemia.

Dessa maneira, o questionário foi dividido em dois blocos: um censitário e outro em relação às suas impressões sobre o Ensino Médio, o curso e especialmente suas percepções sobre a disciplina de Cálculo. Dentre essas questões, as 10 iniciais (bloco 1) eram mais amplas e visavam conhecer atributos do perfil censitário dos discentes, que possuíam respostas abertas ou alternativas pré-definidas. Para as 15 restantes (bloco 2), utilizou-se a

2 - https://cet.ufersa.edu.br/wp-content/uploads/sites/28/2019/08/PPC_CeT_2019.pdf 
escala Likert variando em 5 alternativas de "Concordo muito", "Concordo", "Indiferente", "Discordo" e "Discordo muito".

A escala Likert é simples de construir, fácil interpretação e é uma escala altamente confiável, visto que a elaboração de opções tanto positivas ou negativas não necessariamente precisam ser totalmente precisas, mas mostrar uma percepção da verdade que mostra uma confiabilidade boa (CHAVES, 2012).

Assim, a Tabela 01 apresenta as perguntas do bloco 2, disponíveis no questionário:

Tabela 01: Bloco 2 - Questionário - O perfil dos alunos do curso de Bacharelado em Ciência e Tecnologia e suas impressões sobre Cálculo.

\begin{tabular}{|l|l|}
\hline \multicolumn{1}{|c|}{ Questões } & Alternativas \\
\hline 11 - O Cálculo é útil para minha área de atuação. & Escala Likert \\
\hline $\begin{array}{l}12 \text { - Durante o Ensino Médio, obtive os conhecimentos suficientes em matemática } \\
\text { para me sentir preparado(a) para as disciplinas de Cálculo. }\end{array}$ & Escala Likert \\
\hline 13 - Ao longo do Ensino Médio, estudava Matemática fora do horário de aula. & Escala Likert \\
\hline $\begin{array}{l}14 \text { - Tenho facilidade em resolver situações-problemas que envolvem conceitos } \\
\text { matemáticos. }\end{array}$ & Escala Likert \\
\hline 15 - Estudo com antecedência para as provas. & Escala Likert \\
\hline 16 - Sou participativo durante as aulas. & Escala Likert \\
\hline 17 - Tiro dúvidas sobre o conteúdo com o(a) professor(a). & Escala Likert \\
\hline 18 - Tenho tempo para estudar. & Escala Likert \\
\hline 19 - O curso de Ciência e Tecnologia é o que sempre desejei cursar. & Escala Likert \\
\hline 20 - Tive facilidade em me adaptar ao ritmo de estudo exigido pela Universidade. & Escala Likert \\
\hline $\begin{array}{l}21 \text { - O que me levou a cursar Ciência e Tecnologia (e, posteriormente, Engenharia) } \\
\text { foi minha facilidade com números. }\end{array}$ & Escala Likert \\
\hline 22 - Gosto de matemática. & Escala Likert \\
\hline 23 - Consigo organizar meus horários de estudo. & Escala Likert \\
\hline 24 - Respondo as listas de exercícios sugeridas pelo(a) professor(a). & Escala Likert \\
\hline 25 - A minha aprendizagem em matemática durante o Ensino Médio foi satisfatória. & Escala Likert \\
\hline
\end{tabular}

Fonte: Autores (2020)

A partir dessa aplicação, o questionário obteve 78 respostas. De acordo com dados colhidos com a Coordenação do Curso em questão, o curso de BCT da instituição pesquisada possui 533 discentes com matrícula ativa até o período 2020.1 - sendo essa a população a ser analisada em nossa pesquisa -, subdivididos 502 discentes ativos no Noturno e 31 remanescentes do curso Integral, atualmente retirado da grade disponibilizada através do SISU. A partir desses valores, vê-se pelo cálculo do tamanho de amostra de uma população finita, conforme apresentado por Luchesa e Chaves Neto (2011), que a presente pesquisa possui uma margem de erro de $8.64 \%$ com nível de confiança de $90 \%$.

Segundo Almeida et al. (2010), pode-se também analisar a confiabilidade do questionário a partir do cálculo do alfa de Cronbach, dada pela expressão 
questionário. A pesquisa realizada para tal trabalho apresentou o alfa de Cronbach igual a $77 \%$. Os autores ainda orientam que o valor de alfa de Cronbach é tido como aceitável quando está entre $70 \%$ e $90 \%$, uma vez que abaixo do valor inicial indica a existência de inconsistências internas na escala utilizada, bem como acima do valor de $90 \%$ expõe redundância nos elementos analisados.

Para estudo dos resultados da pesquisa, utilizou-se a análise fatorial com auxílio do programa estatístico PSPP para as que apresentavam a escala Likert. Para análise optou-se pela busca dos componentes principais, aliada a uma abordagem qualitativa. Segundo Costa et al. (2018), a Análise Fatorial Exploratória detém de um dos mais cautelosos métodos para se ter uma análise não abstrata, onde se constrói, a partir de um conjunto de variáveis, uma visão estatística profunda de dados e suas correlações, consolidando assim a formação de fatores que sobre os quais as questões convergem.

Não obstante, realizou-se pesquisa bibliográfica para embasamento sobre a temática. Para tais, pesquisou-se no Google Acadêmico e Periódicos CAPES por "Perfil discente Ensino Superior" e "Perfil estudante Ciências Exatas". A partir desses, realizou-se critérios de inclusão e exclusão visando artigos, trabalhos de conclusão de curso, monografias ou teses que atendessem suficientemente a temática.

\section{Desenvolvimento}

Nessa vertente, serão utilizados métodos estatísticos para uma melhor percepção da realidade dos discentes de CeT a partir da compreensão dos dados colhidos em questionário. Dessa forma, é interessante ressaltar que os dados apresentados a seguir possuem apenas verdade plena em relação a amostra dos discentes analisados, porém, a partir da inferência estatística, é possível estimar as características de toda população a partir das características vistas na amostra. Em relação às questões do Bloco 1, as mesmas visam identificar fatores censitários comuns aos devidos estudantes. Neste agrupamento, pode-se ressaltar os resultados obtidos em cinco questões. As demais estarão contidas no Anexo 1 para apreciação dos leitores do presente trabalho. O primeiro parâmetro com resultados instigantes a serem analisados se refere a idade dos discentes matriculados neste curso, sob os quais obteve-se 77 respostas válidas mostradas no gráfico a seguir:

\section{2 - Qual sua idade?}

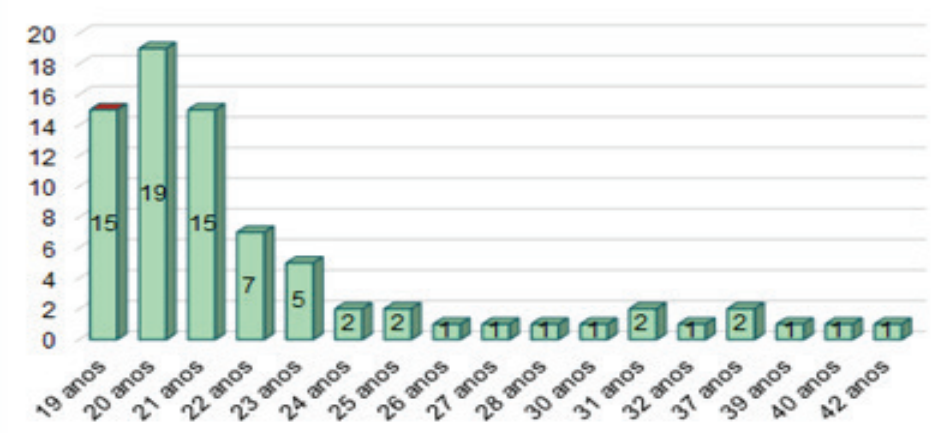

Gráfico 01: Idade dos alunos do curso de Ciência e Tecnologia

Fonte: Autores (2020) 
Por meio deste, vê-se uma distribuição de dados assimétrica à direita ou positiva, na qual a cauda da distribuição está do lado direito do gráfico e temos a seguinte relação: Por essa análise, garante-se que a amostra do público analisado corresponde a discentes jovens, nos quais estima-se que aproximadamente $75 \%$ dos alunos possuem idade igual ou inferior a 23 anos.

A partir dessa questão, todas as demais possuíram 78 respostas válidas. Partindo para análise da $3^{\mathrm{a}}$ questão do questionário (Gráfico 02), nota-se que entre os discentes em análise, obteve-se um maior percentual de indivíduos do sexo masculino. Bahia e Laudares (2013) abordam sobre o discurso social sobre a Masculinidade dos cursos de Engenharias ainda presente na conjuntura atual. Os autores enfatizam o aumento percentual de mulheres nos cursos de engenharia, embora a inserção feminina em modalidades mais tradicionais, como engenharia elétrica e mecânica, ainda seja muito pequena. Assim, justifica-se o afastamento das mulheres na engenharia pelas barreiras sociais que lhes são impostas a partir de discursos machistas, sobrecarregados de descrenças e desvalorização do trabalho da mulher. Entretanto, mesmo com escopo reduzido, a presença feminina vem ganhando cada vez mais espaço na área tecnológica e na luta contra estereótipos que segregam a mulher desses campos de trabalho.

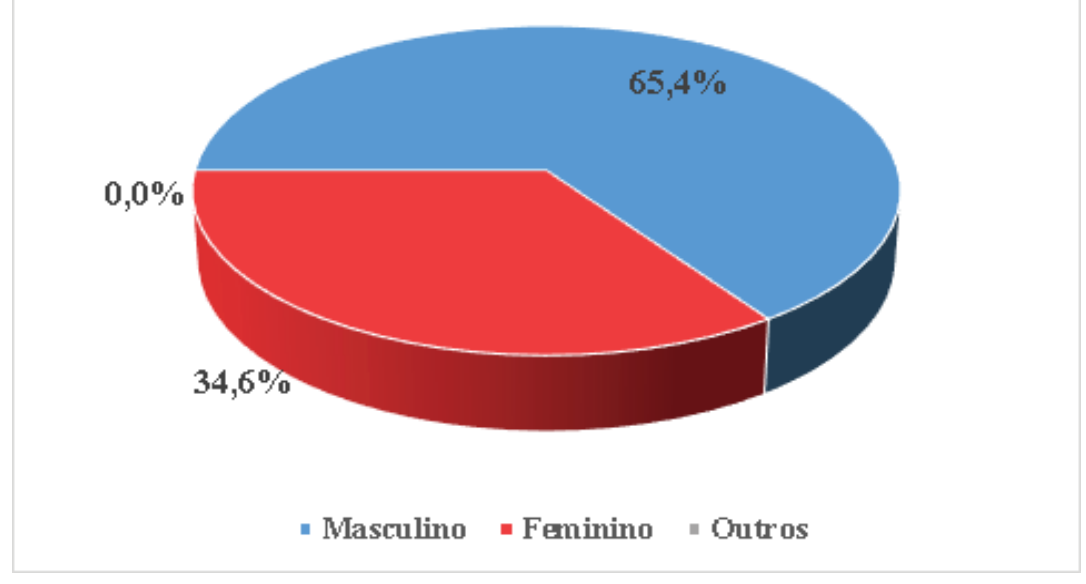

Gráfico 02: Gênero dos discentes Ciência e Tecnologia

Fonte: Autores (2020)

Não obstante, pode-se visualizar características socioeconômicas dos discentes a partir do Gráfico 03, que apresenta a perspectiva da renda familiar. O gráfico atrai a atenção a característica que apenas $12,9 \%$ dos entrevistados (aproximadamente 10 alunos das 78 respostas válidas) possuem renda familiar acima de 3 salários mínimos. Ou seja, pode-se compreender que o curso de BCT tem como público-alvo predominante famílias de classe média-baixa, onde pode-se afirmar que o objetivo da criação desta universidade foi cumprido, que é proporcionar educação de ensino superior ao interior do estado. Este local é predominado por pessoas simples, e a concepção desta universidade evita a evasão de diversas pessoas para outras cidades em busca de uma formação acadêmica. 
- até 1 salário mínimo (até $R \$$

$1.045,00)$

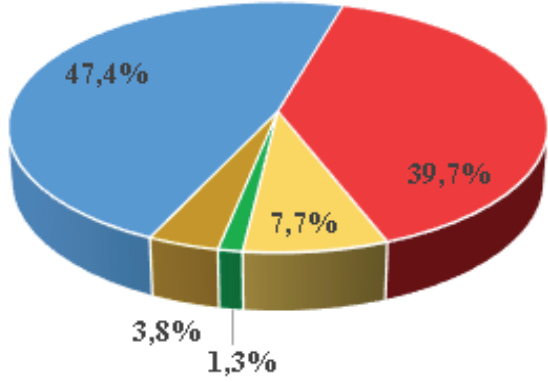

- de 1 a 3 salários mínimos (de $R \$ 1.045,01$ a $R \$$ $3.135,00$ )

de 3 a 5 salários mínimos (de $\mathrm{R} \$ 3.135,01$ a $\mathrm{R} \$$ $5.225,00$ )

- de 5 a 7 salários mínimos (de $R \$ 5.225,01$ a $R \$$ $7.315,00)$

- mais de 7 salários mínimos ( $\mathbf{R} \$ 7.315,01$ ou mais)

Gráfico 03: Renda familiar discentes de Ciência e Tecnologia

Fonte: Autores (2020)

Já em relação ao ano que os discentes concluíram o Ensino Médio como apresentado no Gráfico 04, vê-se uma distribuição de dados assimétrica à esquerda ou negativa na qual temos a seguinte relação: . Diante disso, pode-se verificar que, fazendo um paralelo com o obtido no Gráfico 01 , os discentes de CeT em sua maioria (75\%) correspondem a alunos que concluíram o Ensino Médio nos últimos 6 anos e já ingressaram no curso referido, o que complementa a percepção de se tratar de um público jovem em sua primeira graduação.

\section{7 - Em que ano você terminou o Ensino Médio?}

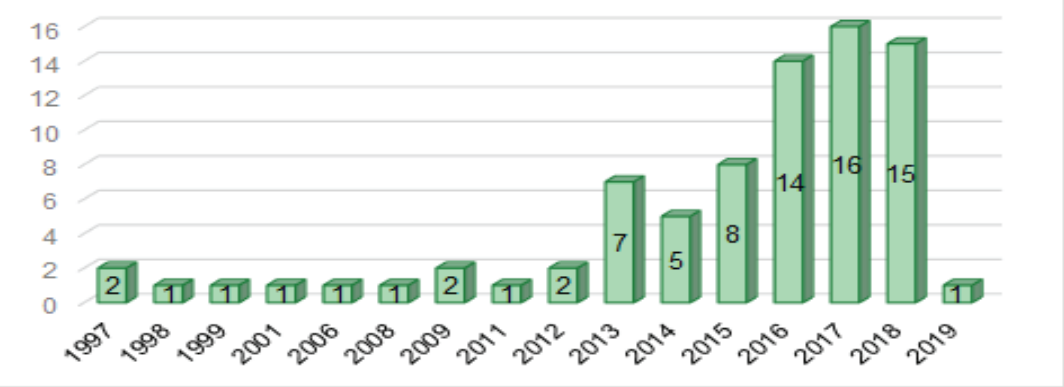

Gráfico 04: Ano de conclusão do Ensino Médio dos discentes de Ciência e Tecnologia

Fonte: Autores (2020)

Finalizando a análise das questões do Bloco 1, o Gráfico 05 apresenta sobre a modalidade escolar que os discentes cursaram o Ensino Médio, no qual é evidente que a maioria (76,9\%) cursou integralmente em instituições públicas. Fazendo-se uma relação com os dados do Gráfico 03, vemos que tais fatos se complementam, nos quais, como na maior parte das famílias da classe social média-baixa, os discentes cursaram grande parte da sua vida acadêmica em instituições públicas. 


\section{8 - O seu ensino médio foi em:}
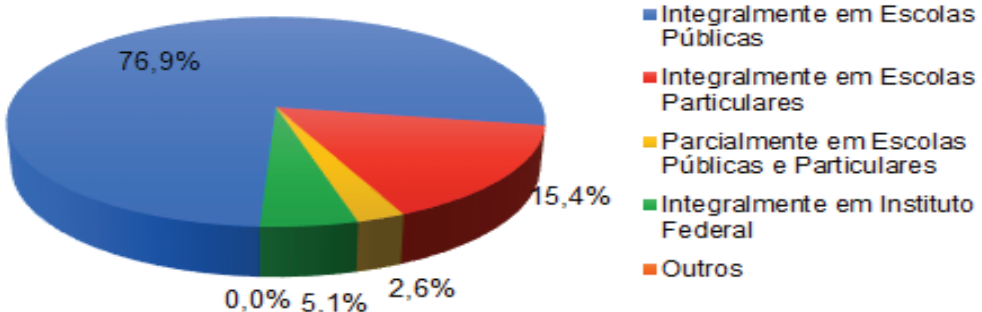

Gráfico 05: Classificação da instituição do Ensino Médio dos discentes de Ciência e Tecnologia

Fonte: Autores (2020)

Partindo para a análise das questões do segundo bloco, realizou-se a análise fatorial e notou-se a consolidação de quatro perfis comuns aos discentes de Ciência e Tecnologia analisados, perfis estes que representam $61,99 \%$ do conjunto total. Nota-se, de forma direta, que os resultados inferidos constituem de grande valor significativo e descritivo, haja visto que o público a ser analisado é bem diversificado em objetivos e necessidades de ensino.

Assim, pode-se agrupar as perguntas da Tabela $1 \mathrm{e}$, com os resultados da análise fatorial, consolidar a formação dos seguintes perfis dos discentes:

Tabela 02: Questões Escala Likert agrupadas em fatores

\begin{tabular}{|c|c|c|c|c|c|}
\hline Questões & Fator 1 & Fator 2 & Fator 3 & Fator 4 & Perfil \\
\hline $\begin{array}{l}12 \text { - Durante o Ensino Médio, obtive os conhecimentos suficientes em } \\
\text { matemática para me sentir preparado(a) para as disciplinas de Cálculo. }\end{array}$ & 0,9 & & & & \multirow{3}{*}{$\begin{array}{l}\text { Bons resultados } \\
\text { no Ensino Médio }\end{array}$} \\
\hline $\begin{array}{l}13 \text { - Ao longo do Ensino Médio, estudava Matemática fora do horário } \\
\text { de aula. }\end{array}$ & 0,53 & & & & \\
\hline $\begin{array}{l}25 \text { - A minha aprendizagem em matemática durante o Ensino Médio } \\
\text { foi satisfatória. }\end{array}$ & 0,84 & & & & \\
\hline 15 - Estudo com antecedência para as provas. & & 0,66 & & & \multirow{5}{*}{$\begin{array}{l}\text { Organizado } \\
\text { e com tempo } \\
\text { disponível }\end{array}$} \\
\hline 18 - Tenho tempo para estudar. & & 0,58 & & & \\
\hline $\begin{array}{l}20 \text { - Tive facilidade em me adaptar ao ritmo de estudo exigido pela } \\
\text { Universidade. }\end{array}$ & & 0,51 & & & \\
\hline 23 - Consigo organizar meus horários de estudo. & & 0,8 & & & \\
\hline 24 - Respondo as listas de exercícios sugeridas pelo(a) professor(a). & & 0,79 & & & \\
\hline 16 - Sou participativo durante as aulas. & & & 0,87 & & \multirow{2}{*}{ Participativo } \\
\hline 17 - Tiro dúvidas sobre o conteúdo com o(a) professor(a). & & & 0,91 & & \\
\hline 11 - 0 Cálculo é útil para minha área de atuação. & & & & 0,52 & \multirow{5}{*}{$\begin{array}{l}\text { Identificação com } \\
\quad 0 \text { curso }\end{array}$} \\
\hline $\begin{array}{l}14 \text { - Tenho facilidade em resolver situações-problemas que envolvem } \\
\text { conceitos matemáticos. }\end{array}$ & & & & 0,7 & \\
\hline 19 - O curso de Ciência e Tecnologia é o que sempre desejei cursar. & & & & 0,7 & \\
\hline $\begin{array}{l}21 \text { - } 0 \text { que me levou a cursar Ciência e Tecnologia (e, posteriormente, } \\
\text { Engenharia) foi minha facilidade com números. }\end{array}$ & & & & 0,78 & \\
\hline 22 - Gosto de matemática. & & & & 0,74 & \\
\hline
\end{tabular}

Fonte: Autores (2020) 
Com isso, pode-se apresentar os fatores a se consolidarem como perfis desse grupo bem como a carga fatorial associada às perguntas que levaram a consolidação destes grupos. De acordo com Laros (2005), a carga fatorial representa quantos por cento de covariância existe entre um fator e uma questão (chamada de variável). Como demonstrado por Peixoto e Kleinke (2016), o valor absoluto da carga fatorial representa uma relação diretamente proporcional entre a questão e o perfil a ser constituído. Ainda segundo estes autores, é interessante considerar-se para análise apenas fatores acima de 0,5 visando uma melhor caracterização destes perfis, dinâmica também utilizada no presente trabalho. Outro ponto a ser observado é que o valor da carga fatorial varia de -1 a 1 , e os valores negativos indicam que a maioria dos respondentes não concordam com a afirmação, o que não é o caso na tabela anteriormente apresentada.

A ordem em que os fatores são apresentados também é importante, pois constitui uma escala decrescente em relação a representatividade de discentes que se adequam àquele grupo, ou seja, o fator 1 descreve uma quantidade maior de alunos do que o fator 2, por exemplo. Dessa forma, através da análise dos componentes principais, agrupou-se as 15 questões em 4 grupos a fim de explicitar as variáveis latentes para obtenção dos 4 perfis encontrados. Variáveis latentes são variáveis que não são diretamente observáveis, isto é, para medi-las precisa-se de um conjunto de variáveis mensuráveis. Por exemplo, as perguntas 12,13 e 25 da tabela 2 estão associadas a um valor numérico (ou seja, são mensuráveis) e representam, em conjunto, concepções acerca do ensino médio, que foi relacionado a "base do ensino médio qualificada". A vantagem desse processo é que se pode descrever os participantes a partir de uma quantidade menor de variáveis. Esses agrupamentos, que foram denominados perfis, são bem comuns dentre os indivíduos em análise, os quais permitem a discussão a seguir:

Perfil 1: De acordo com as respostas ao questionário, os discentes demonstraram acreditar que aparentemente tiveram uma boa base em matemática no Ensino Médio, o que entra em conflito com a ideia proferida acima sobre os níveis de reprovação na disciplina de Cálculo I. Diante desse fato, esse fator ainda pondera que os índices de reprovação em Cálculo possivelmente estão relacionados ao desnivelamento entre o Ensino Médio e Superior, no qual os alunos escolheram o curso pela familiaridade que tinham em matemática e acreditavam que tinham os conhecimentos suficientes em Matemática que findam-se não tão consolidados ao se deparar com a alta carga de abstração e demonstração encontradas em disciplinas como Cálculo. Assim, autores como Bellettini e Souza (2018) defendem a implementação de projetos como pré-cálculo, matemática zero e monitorias como essenciais ao nivelamento no Ensino Superior e preenchimento de lacunas deixadas por defasagens no Ensino Médio, enquanto no outro extremo autores como Silva e Sousa (2014) acreditam na implementação de conceitos básicos de limites, derivadas e integrais ainda no Ensino Médio para o engajamento na maturidade matemática desde esse nível de ensino, haja visto que as duas concepções são estratégias passíveis a diminuir a discrepância entre o Ensino Médio e Superior. Logo, o primeiro perfil de alunos de CeT, o qual constitui a maior parte desses discentes, mostra que os alunos acreditam na importância da formação de uma base qualificada de matemática durante o Ensino Médio para obter sucesso nas disciplinas de 
Cálculo durante o Ensino Superior, ideia também defendida por autores como Silva (2013) e Flores et al. (2018).

Perfil 2: O segundo perfil engloba os alunos que possuem boa organização e disponibilidade para estudar os conteúdos trabalhados no curso. Isso demonstra que, apesar de constituir um curso noturno onde alguns discentes possuem ocupações diárias, possui-se um grupo significativo que consegue controlar seus afazeres e ter tempo para realização das listas de exercícios e estudar para provas. Assim, esse fator sensibiliza que, acerca dos insucessos em Cálculo I, esse tempo de estudo pode estar se dando de maneira ineficaz, seja por distrações no momento de estudo, por dificuldades em aprender o conteúdo pela metodologia adotada ou ainda pelo mau gerenciamento do tempo de forma geral. Alves e Oliveira (2018) expõem a diferença entre estudar e aprender, onde revelam que não necessariamente quando se estuda, se aprende. O aprender é algo intrínseco no ser humano, no qual dos primeiros aos últimos momentos de vida o ser humano destina-se a aprender. Já estudar é buscar técnicas para aprender, que podem ou não assegurar um aprendizado contínuo e firme. Então, ter tempo e estudar não necessariamente podem ser suficientes para obter índices positivos no componente curricular.

Perfil 3: Já o terceiro perfil constitui aos alunos que, independentemente da disponibilidade de horários, visam sanar suas dúvidas em sala de aula ou em momentos oportunos com os docentes. Destarte, é possível ressaltar que não necessariamente esse aluno tenha tempo livre para um estudo extra, podendo pontuar que o aluno tira dúvidas pelas dificuldades herdadas como também pela dificuldade no conteúdo do componente curricular, o qual tenta se dedicar o máximo possível. Porém, a justificativa para os altos níveis de reprovação em face a este perfil não se limita somente a isso, pois ainda pode estar ocorrendo uma limitação com a comunicação professor-aluno, que interfere ao ponto que o conteúdo dado em sala de aula não tem uma absorção desejada. Portanto, vê-se que esse perfil autorretrato do aluno de BCT retrata aqueles que buscam compreender o conteúdo somente a partir do que é ministrado em sala de aula e que não se torna suficiente para a aprovação na matéria. Este perfil é o que mais tem potencial para ter resultados positivos em quaisquer componentes curriculares, pois, segundo Meireles et al. (2017), é importante haver uma abertura entre o professor e o aluno para uma construção racional de conhecimento, visto que o compartilhamento de informações de forma natural se torna mais eficaz quando fundamentada em relações sociais e não somente com exercícios isolados.

Perfil 4: Por fim, os discentes do curso de CeT que são explicados por esse fator possuem identificação com o curso de Engenharia e, de maneira geral, gostam do curso ao qual estudam e acreditam que podem se tornar profissionais capacitados a partir dessa formação. Desse modo, as taxas de reprovação podem estar relacionadas ao maior interesse dos discentes para as cadeiras direcionadas para a aplicabilidade da Engenharia e atividades a serem realizadas no campo de trabalho futuramente, não se interessando nas abstrações e procedimentos mostrados em Cálculo. Entretanto, Lopez e Segadas (2014) reforçam a necessidade de o Engenheiro ter aptidões frente ao Cálculo durante toda sua vida profissio- 
nal, pois embora utilizem ferramentas computacionais que o ajudam a realizar o trabalho, é dever do engenheiro compreender os procedimentos matemáticos e corrigi-los, quando necessário. Além disso, os autores ainda remeteram ao fato de o desempenho em Cálculo ter grande correlação com a aprovação dos alunos ao longo de todo curso de Engenharia e, por consequência, sua conclusão. Na amostra, os autores alcançaram que $80 \%$ dos discentes analisados que tinham andamento bom ou ótimo durante o curso de Engenharia foram aprovados em Cálculo I na primeira vez que o cursaram.

\section{CONSIDERAÇões FINAIS}

Diante do exposto, traçou-se mecanismos sobre os quais foi-se possível a consolidação de um perfil autorretrato que explica a maior parte dos estudantes de Ciência e Tecnologia de uma Universidade do Alto-Oeste Potiguar. A partir do apresentado, vê-se que tal público é composto em sua maioria por homens jovens de até 27 anos, porém que a inserção feminina tem tomado destaque, igualmente o que ocorre nas demais faculdades de Engenharias brasileiras. Viu-se que, em geral, são alunos de classe baixa-média e que cursaram maior parte de sua vida em instituições públicas. Pode-se afirmar, assim, a importância da presença de universidades em regiões interioranas, que possibilitam expandir o conhecimento para pessoas de origem simples, contribuir com o avanço da ciência em pequenas cidades e gerar profissionais capacitados fora das regiões metropolitanas, possibilitando a geração de empregos nessas áreas.

Em relação ao Cálculo e tipologias de discentes analisadas, viu-se que se destacam 4 perfis que exprimem o que são os discentes de Ciência e Tecnologia: alunos que gostam de estudar matemática, que possuem tempo disponível para estudo, que se utilizam do vínculo professor-aluno como ferramenta de estudo e, por fim, alunos que gostam da Engenharia e suas aplicações. Em análise do rendimento desses discentes frente ao cálculo, apresentou-se ao longo do presente trabalho justificativas frente aos perfis formados, porém ainda é necessário ressaltar outras causas desses resultados, como falta de motivação por causas pessoais, distrações e emoções que o discente pode estar passando. Sabe-se que esses podem ser resolvidos quando investigados, aplicando uma metodologia compatível ao problema, pois "conhecer o perfil do aluno favorece a implementação de estratégias para aprendizagem, além de garantir maior eficiência no processo que vai do planejamento ao desenvolvimento e direcionamento do curso" (GOMES et al., 2014, p. 355).

Assim, o presente trabalho procurou apresentar subsídios necessários para a reflexão e compreensão do perfil dos discentes do curso de Bacharelado em Ciência e Tecnologia analisado, mostrando-se como ponto de partida para a consolidação de novas estratégias de ensino direcionadas para esse grupo. Nessa vertente, vê-se a necessidade de pautar novas metodologias guiadas pelo público-alvo, respeitando suas motivações, dificuldades e carências. 


\section{REFERÊNCIAS}

ALVES, D.; OLIVEIRA, P. de T. APRENDENDO A ESTUDAR: um olhar científico sobre as formas de estudo. In: $18^{\circ}$ CONGRESSO NACIONAL DE INICIAÇÃO CIENTÍFICA, [s.1.], Anais [...], CONIC, p. 1-20, 2018.

ALMEIDA, D.; SANTOS, M. A. R; COSTA, A. F. B. Aplicação do coeficiente alfa de Cronbach nos resultados de um questionário para avaliação de desempenho da saúde pública. In: ENCONTRO NACIONAL DE ENGENHARIA DE PRODUÇÃO, 30., 2010, São Carlos. Anais [...], São Carlos, 2010.

ARAUJO, E. A. de. O PERFIL DE ALUNOS DA ÁREA DE CIÊNCIAS EXATAS E ENGENHARIAS E A QUALIDADE DE ENSINO. Revista de Educação PUC-Campinas, Campinas, n. 12, p. 61-75, 2002.

AZEVEDO, ÉRICA DE M. Análise do Perfil dos Alunos Ingressantes de um Curso de Licenciatura em Química Semipresencial de um Polo do Sistema UAB: Um Guia Acerca das Publicações sobre o Tema em Questão. EaD em Foco, v. 10, n. 2, 4 nov. 2020.

BAHIA, M. M.; LAUDARES, J. B. A ENGENHARIA E A INSERÇÃO FEMININA. In: SEMINÁRIO INTERNACIONAL FAZENDO GêNERO 10, Florianópolis. Anais [...]. Florianópolis: Fazendo Gênero 10; Desafios Atuais dos Feminismos, p. 1-11, 2013.

BELLETTINI, M. T.; SOUZA, S. de. A IMPLANTAÇÃO DA DISCIPLINA DE PRÉ-CÁLCULO COMO POLÍTICA PEDAGÓGICA DE PERMANÊNCIA NOS CURSOS DE GRADUAÇÃO DO CENTRO TECNOLÓGICO DA UFSC. In: XVIII COLÓQUIO INTERNACIONAL DE GESTÃO UNIVERSITÁRIA, Santa Catarina, Anais [...], Universidade Federal de Santa Catarina, p. 1-13, 2018.

BEZERRA, W.; GONTIJO, C. PERCEPÇÕES DE PROFESSORES DE CÁLCULO 1 SOBRE A AVALIAÇÃO E SUAS RELAÇÕES COM AS APRENDIZAGENS DOS ESTUDANTES. Revista Paranaense de Educação Matemática, [s.1.], v. 9, n. 19, p. 538$554,2020$.

BRASIL. TODOS PELA EDUCAÇÃO. Aprendizado adequado em matemática no Ensino Médio é 21 vezes maior para estudantes de nível socioeconômico mais alto; dados são do monitoramento da Meta 3 do Todos Pela Educação. Brasília: MEC/TPE, 2019a. Disponível em: https://www.todospelaeducacao.org.br/conteudo/meta-3-em-10-anos-aprendizado-adequado-ensino-medio-segue-estagnado-avancos-5-ano-fundamental. Acesso em: 17 junho 2020.

BRASIL. Projeto Pedagógico do curso Interdisciplinar em Ciência e Tecnologia, Universidade Federal Rural do Semi-Árido, Mossoró, 2019b. Disponível em: https://cet.ufer- 
sa.edu.br/wp-content/uploads/sites/28/2019/08/PPC_CeT_2019.pdf. Acesso em: 04 abril 2020 .

BZUNECK, J. A. Emoções acadêmicas, autorregulação e seu impacto sobre motivação e aprendizagem. ETD - Educação Temática Digital, Universidade Estadual de Campinas, [s.l.], v. 20, n. 4, p. 1059-1075, 2018.

\section{CHAVES, L. O IMPACTO DO FORMATO DE APLICAÇÃO DO QUESTIONÁRIO}

NO RESULTADO. 2012. 44 f. Monografia (Especialização) - Curso de Pesquisa de Mercado Aplicada em Comunicações, Departamento de Relações Públicas, Propaganda e Turismo da Escola de Comunicações e Artes, Universidade de São Paulo, São Paulo, 2012.

COSTA, L. de F. L. G. da; MOL, A. L. R.; AÑEZ, M. E. M.; DAMASCENO, T. dos S. Z. Desempenho internacional de empresas exportadoras: uma análise fatorial baseada em recursos. Revista Principia - Divulgação Científica e Tecnológica do IFPB, [S.1.], n. 41, p. 128-138, 2018.

COUTINHO, K. S.; PASSERINO, L. M.; HENRIQUES, R. B.; AVILA, M. M. Práticas pedagógicas inovadoras no ensino universitário: uma análise da motivação e da percepção dos alunos. Educação Por Escrito, EDIPUCRS, [s.1.], v. 9, n. 2, p. 326-346, 2019.

DAHER, A. F. B. ALUNO E PROFESSOR: protagonistas do processo de aprendizagem. SEMED - Secretaria Municipal de Educação. Campo Grande, p. 1-12, 2017.

EVAngelistA, T. da S.; TOGNETTI, T. C.; AMORIM, R. G. G. de; S. NETO, A. F. MATH GAME: a ludic strategy for differential and integral calculus teaching in engineering courses. Revista de Ensino de Engenharia, [s.1.], v. 37, n. 1, p. 57-65, 2018.

FLORES, J. B.; LIMA, V. M. do R.; MÜLLER, T. J. O uso das Tecnologias da Informação e Comunicação no ensino de Cálculo Diferencial e Integral: reflexões a partir de uma metanálise. Abakós, [s.1.], v. 6, n. 2, p. 21-35, 2018.

GODOI, M. A. de; OLIVEIRA, S. M. da S. S. O perfil do aluno da educação a distância e seu estilo de aprendizagem. Ead em Foco, [s.1.], v. 6, n. 2, p.76-91, 2016.

GOMES, S. G. S.; MOTA, J. B.; LEONARDO, E. S. Reflexão sobre o perfil do aluno como determinante para a motivação e aprendizagem em curso de EaD. Cad. Ed. Tec. Soc., Inhumas, v. 7, p. 355-363, 2014.

LAROS, J. A. O uso da análise fatorial: algumas diretrizes para pesquisadores. In: PASQUALI, L. Análise fatorial para pesquisadores. Brasília: LabPAM, p. 141-160, 2005. LAVOR, O. P.; MARTINS, M. P. de S. Análise das emoções na vida acadêmica: conhecendo e compreendendo. Comunicações, [s.1.], v. 27, n. 1, p. 49-62, 2020. 
LOPEZ, I. F.; SEGADAS, C. A DISCIPLINA CÁLCULO I NOS CURSOS DE ENGENHARIA DA UFRJ: sua relação com o acesso à universidade e sua importância para a conclusão do curso. Revista de Engenharia da Universidade Católica de Petrópolis REUCP, Petrópolis, v. 8, n. 2, p. 92-107, 2014.

LUCHESA, C. J.; CHAVES NETO, A. Cálculo do tamanho da amostra nas pesquisas em Administração. Curitiba: UNICURITIBA, 27 p., 2011.

MEIRELES, D. S. DE L.; MEIRELES, R. F.; TAHIM, A. P. V. DE O.; CARNEIRO, S. N. V. A teoria do agir comunicativo e sua contribuição para a relação professor-aluno no ensino superior. Revista Docência do Ensino Superior, v. 7, n. 2, p. 97-112, 7 dez. 2017.

OLIVEIRA, J. D. de; MADRUGA, Z. E. de F. Mapeamento de produções brasileiras sobre o uso da Modelagem Matemática no ensino de Cálculo Diferencial e Integral. Revista Docência do Ensino Superior, Belo Horizonte, v. 8, n. 2, p. 211-227, 2018.

OLIVEIRA, M. C. A. de; RAAD, M. R. A existência de uma cultura escolar de reprovação no ensino de Cálculo. Boletim GEPEM, Juiz de Fora, n. 61, p. 125-137, 2012.

OLIVEIRA, R. P. de; SILVA, L. C. S. da; MAIA, F. O. ESTUDANTES INGRESSANTES NA UNIVERSIDADE: um estudo do perfil dos alunos de engenharia de produção da Universidade Federal de Goiás (UFG). In: XLIV CONGRESSO BRASILEIRO DE EDUCAÇÃO EM ENGENHARIA, Anais [...]. Natal: Associação Brasileira de Educação em Engenharia (ABENGE), p. 1-9, 2016.

PEIXOTO, D. E.; KLEINKE, M. U. EXPECTATIVAS DE ESTUDANTES SOBRE AASTRONOMIA NO ENSINO MÉDIO. Revista Latino-americana de Educação em Astronomia - RELEA, [s.1], n. 22, p. 21-34, 2016.

RAFAEL, R. C. Cálculo Diferencial e Integral: um estudo sobre as estratégias para redução do percentual de não aprovação. 2017. 103 f. Dissertação (Mestrado) - Curso de Mestrado Profissional em Educação Matemática, Universidade Federal de Juiz de Fora, Juiz de Fora, 2017.

ROSA, C. de M.; ALVARENGA, K. B.; SANTOS, F. F. T. dos. Desempenho acadêmico em cálculo diferencial e integral. Revista Internacional de Educação Superior, [s.1.], v. 5, p. 1-16, 2019.

SILVA, C. R. da; SOUSA, K. R. de Q. CÁlCULO: uma proposta possível para o ensino médio. Revista Panorâmica On-line, Barra do Garças, v. 17, p. 81-89, 2014.

SILVA, J. M. da. O ensino do conteúdo Funções na escola de Ensino Médio José Paulo de França da cidade de Mari - PB: o que dizem os professores? TCC (Graduação) - Curso de Licenciatura em Matemática A Distância, Universidade Federal da Paraíba, Mari, 2013. 
SCHMIDT, B.; PALAZZI, A.; PICCININI, C. A. Entrevistas online: potencialidades e desafios para coleta de dados no contexto da pandemia de COVID-19. REFACS, Uberaba, MG, v. 8, n. 4, p. 960-966, 2020. Disponível em: http://seer.uftm.edu.br/revistaeletronica/ index.php/refacs/article/view/4877. Acesso em: 01 de abril de 2021.

TREVISAN, A. L.; MENDES, M. T. Ambientes de ensino e aprendizagem de cálculo diferencial e integral organizados a partir de episódios de resolução de tarefas: uma proposta. Revista Brasileira de Ensino de Ciência e Tecnologia, [s.1.], v. 11, n. 1, p. 209-227, 2018.

\section{DADOS DOS AUTORES}

\section{Davi Euclides de Oliveira}

Bacharelando Interdisciplinar em Ciência e Tecnologia pela Universidade Federal Rural do Semi-Árido. Pau dos Ferros, Rio Grande do Norte/RN-Brasil. davi.oliveira@alunos. ufersa.edu.br

\section{JANNESON José FERREIRA de LiMA}

Bacharelando Interdisciplinar em Ciência e Tecnologia pela Universidade Federal Rural do Semi-Árido. Pau dos Ferros, Rio Grande do Norte/RN-Brasil. janneson.lima@alunos. ufersa.edu.br

\section{Paulo Henrique das Chagas Silva}

Doutorando pelo Programa de Pós-Graduação Multiunidades em Ensino de Ciências e Matemática da Universidade Estadual de Campinas. Professor da Universidade Federal Rural do Semi-Árido. Pau dos Ferros, Rio Grande do Norte/RN-Brasil.paulo.silva@ufersa.edu.br

Submetido em: 31-07-2020

Aceito em: 01-07-2021 
ANEXOS

Questionário completo

\begin{tabular}{|c|c|}
\hline Questões & Alternativas \\
\hline 1 - Semestre de ingresso: & Resposta curta aberta. \\
\hline 2 - Qual sua idade? & Resposta curta aberta. \\
\hline 3 - Qual é o seu gênero? & $\begin{array}{l}\text { Feminino; Masculino; Prefiro não dizer; } \\
\text { Outros. }\end{array}$ \\
\hline 4 - Qual sua renda familiar? & $\begin{array}{l}\text { Até } 1 \text { salário mínimo (até R\$ 1.045,00); de } \\
1 \text { a } 3 \text { salários mínimos (de R\$ 1.045,01 a } \\
\mathrm{R} \$ 3.135,00) \text { ) de } 3 \text { a } 5 \text { salários mínimos } \\
\text { (de } \mathrm{R} \$ 3.135,01 \text { a } \mathrm{R} \$ 5.225,00) ; \text { de } 5 \text { a } 7 \\
\text { salários mínimos (de R\$ 5.225,01 a R\$ } \\
\text { 7.315,00); mais de } 7 \text { salários mínimos (R\$ } \\
\text { 7.315,01 ou mais). }\end{array}$ \\
\hline 5 - Em qual estado você mora? & $\begin{array}{l}\text { Rio Grande do Norte; Ceará; Paraíba; Ou- } \\
\text { tros. }\end{array}$ \\
\hline $\begin{array}{l}6 \text { - Você exerce alguma atividade remunerada? Se sim, ela } \\
\text { possui alguma relação com o Curso? }\end{array}$ & $\begin{array}{l}\text { Sim, e possui relação com curso; Sim, mas } \\
\text { não possui relação com curso; Não. }\end{array}$ \\
\hline 7 - Em que ano você terminou o Ensino Médio? & Resposta curta aberta. \\
\hline 8 - O seu ensino médio foi em: & $\begin{array}{l}\text { Integralmente em Escolas Públicas; Inte- } \\
\text { gralmente em Escolas Particulares; Parcial- } \\
\text { mente em Escolas Públicas e Particulares; } \\
\text { Integralmente em Instituto Federal; Outros. }\end{array}$ \\
\hline 9 - Você já possui algum diploma de graduação? & Sim; Não. \\
\hline $\begin{array}{l}10 \text { - O bacharelado em Ciência e Tecnologia foi sua } 1^{\mathrm{a}} \\
\text { opção no Sisu? }\end{array}$ & Sim; Não. \\
\hline 11 - O Cálculo é útil para minha área de atuação. & Escala Likert. \\
\hline $\begin{array}{l}12 \text { - Durante o Ensino Médio, obtive os conhecimentos } \\
\text { suficientes em matemática para me sentir preparado(a) } \\
\text { para as disciplinas de Cálculo. }\end{array}$ & Escala Likert. \\
\hline $\begin{array}{l}13 \text { - Ao longo do Ensino Médio, estudava Matemática } \\
\text { fora do horário de aula. }\end{array}$ & Escala Likert. \\
\hline $\begin{array}{l}14 \text { - Tenho facilidade em resolver situações-problemas } \\
\text { que envolvem conceitos matemáticos. }\end{array}$ & Escala Likert. \\
\hline 15 - Estudo com antecedência para as provas. & Escala Likert. \\
\hline 16 - Sou participativo durante as aulas. & Escala Likert. \\
\hline 17 - Tiro dúvidas sobre o conteúdo com o(a) professor(a). & Escala Likert. \\
\hline 18 - Tenho tempo para estudar. & Escala Likert. \\
\hline $\begin{array}{l}19 \text { - O curso de Ciência e Tecnologia é o que sempre de- } \\
\text { sejei cursar. }\end{array}$ & Escala Likert. \\
\hline $\begin{array}{l}20 \text { - Tive facilidade em me adaptar ao ritmo de estudo } \\
\text { exigido pela Universidade. }\end{array}$ & Escala Likert. \\
\hline $\begin{array}{l}21 \text { - O que me levou a cursar Ciência e Tecnologia (e, } \\
\text { posteriormente, Engenharia) foi minha facilidade com nú- } \\
\text { meros. }\end{array}$ & Escala Likert. \\
\hline 22 - Gosto de matemática. & Escala Likert. \\
\hline 23 - Consigo organizar meus horários de estudo. & Escala Likert. \\
\hline $\begin{array}{l}24 \text { - Respondo as listas de exercícios sugeridas pelo(a) } \\
\text { professor(a). }\end{array}$ & Escala Likert. \\
\hline $\begin{array}{l}25 \text { - A minha aprendizagem em matemática durante o En- } \\
\text { sino Médio foi satisfatória. }\end{array}$ & Escala Likert. \\
\hline
\end{tabular}

Fonte: Autores (2020) 